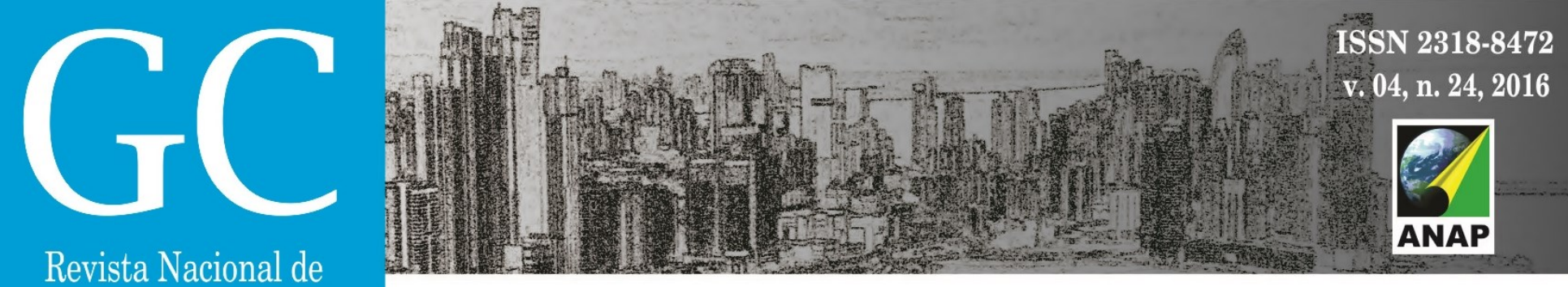

Gerenciamento de Cidades

National Jounal of Cities Management

\title{
A utilização do Marketing Urbano no Planejamento Estratégico do Rio de Janeiro.
}

The use of Urban Marketing in Strategic Planning of Rio de Janeiro.

El uso del marketing urbano en Planificación Estratégica de Río de Janeiro.

Geise Brizotti Pasquotto

Doutora, USP, Brasil

geisebp@gmail.com 


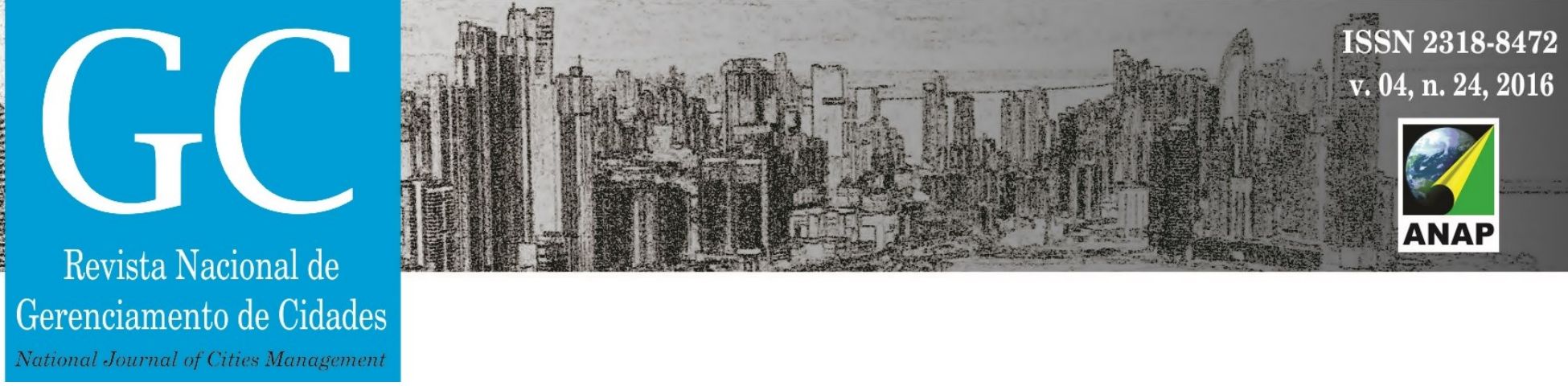

\section{RESUMO}

O marketing urbano e o planejamento estratégico vem sendo utilizados em uma dinâmica onde a produção, consumo e lucro são os aspectos esperados como resultado das ações do poder público. A promoção urbana recria novas imagens para serem vendidas no mercado global para readequá-las às novas necessidades locais. O presente artigo busca analisar como o marketing urbano está inserido nos planejamentos estratégicos do Rio de Janeiro. Para tanto, a metodologia utilizada foi verificar nestes planos a existência dessa política e/ou a presença das ferramentas do marketing urbano e analisar como a política de promoção urbana foi utilizada em gestões diferentes ao longo dos anos.

PALAVRAS-CHAVE: Planejamento Estratégico, Rio de Janeiro, Marketing Urbano.

\section{ABSTRACT}

The urban marketing and the strategic planning have been used in a dynamic which the production, consumption and profit are the expected aspects as results of public power actions. The urban promotion recreates new images to be sold in global market, to readjust to the new local necessities. The current paper quests analyse how the urban marketing is inserted into strategic planning of Rio de Janeiro. Therefore, the methodology was verify in these plans the existence of this policy and/or the presence of urban marketing tools and analyse how the politics of urban promotion was used in different managements over the years.

KEYWORDS: Strategic planning, Rio de Janeiro, Urban Marketing.

\section{RESUMEN}

El marketing urbano y la planificación estratégica se han utilizado en una dinámica en que la producción, el consumo y el beneficio son aspectos que se espera como resultado de las acciones de gobierno. La Promoción urbana recrea nuevas imágenes para ser vendidos en el mercado mundial, con el fin de ajustarlos a las nuevas necesidades locales. En este artículo se pretende analizar el impacto del marketing urbano está incrustado en la planificación estratégica de Río de Janeiro. Por lo tanto, la metodología utilizada fue ver nestes textos la existencia de esta política y/o la presencia de herramientas de marketing urbanas y analizar cómo la política de promoción urbana se utilizó en diferentes administraciones en los últimos años.

PALABRAS CLAVE: Planificación Estratégica, Río de Janeiro, Marketing Urbano. 


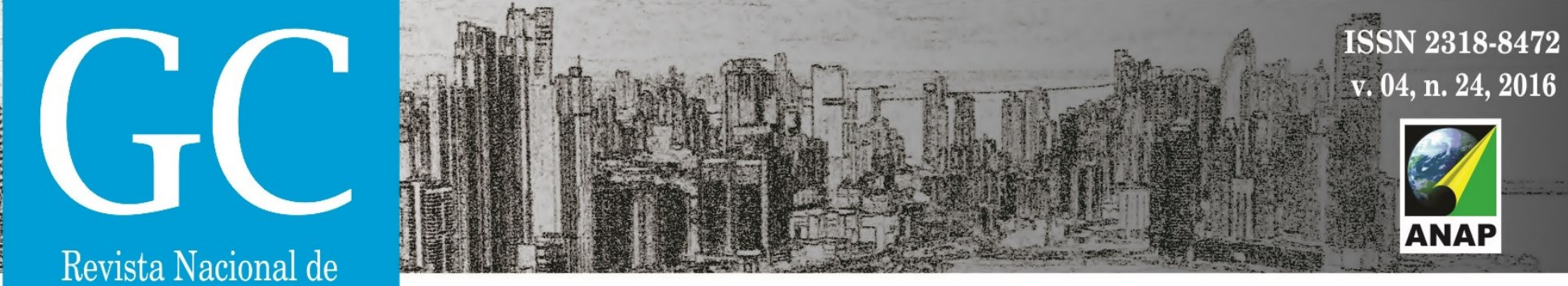

Gerenciamento de Cidades

\section{INTRODUÇÃO}

O poder local, como já apontara Harvey (1996), abandonou a posição prevalente nos anos 1960 de gerenciador da cidade, e adotou, a partir dos anos 1980, uma postura de gestor empresarial pautada no "empreendedorismo urbano", em relação ao desenvolvimento econômico. As cidades passaram a adotar estratégias de desenvolvimento urbano procurando potencializar as oportunidades de atração de investimentos, utilizando-se da política e planejamento urbano estratégico para adequá-las ao contexto mundial.

O Planejamento Estratégico de Cidades desenvolveu-se face a necessidade de compatibilizar os desafios gerados pela nova estruturação da sociedade urbana, em um mundo globalizado, criando novas demandas e aspirações, com a administração do espaço local (LOPES, 1998).

O planejamento estratégico representou uma transposição dos conceitos do planejamento de empresas para o planejamento urbano (KAUFMAN; JACOBS, 1987). A ideia que sustenta o conceito é a de que, no mundo da "acumulação flexível", em que dominam as "novas" dinâmicas econômicas da globalização, as cidades devem ser mais competitivas. Diante de tal pretensa necessidade, elas passam a assegurar seu status no contexto internacional por meio da transformação do espaço urbano em "vitrine", com consequências territoriais marcantes.

Deste modo, as cidades passam a constituir produtos que serão vistos, vendidos e comercializados. Se a forma de exposição ou seu objeto forem bem definidos por ocasião do planejamento estratégico, geralmente a cidade se sobressai no contexto da competição global. O marketing urbano é uma ramificação do planejamento estratégico que trabalha com a promoção e venda das cidades. Essa relação com a "cidade-mercadoria" está cada vez mais sendo utilizado no desenvolvimento e planejamento das cidades de grande porte ou turísticas, adquirindo, segundo Sánchez (1997), uma centralidade no conjunto das novas políticas urbanas, tornando-se o principal instrumento para alavancar os diversos processos de promoção das cidades. E sua emergência e ascensão corroboram uma nova ideologia do planejamento e ação, resultando em uma nova visão de mundo que se estabelece na orientação dessas políticas (SÁNCHEZ, 2003).

Neste contexto onde a produção, consumo e lucro são os aspectos esperados como resultado das ações do poder público e a produção de imagens para o mercado global é algo importante, a cidade do Rio de Janeiro se destaca. Ela foi um dos primeiros municípios brasileiros a utilizar o planejamento estratégico em sua administração, além de convidar consultores catalães com o intuito de difundir os "modelos" espanhóis de promoção urbana para a realidade brasileira na tentativa de adequar o planejamento urbano local a níveis internacionais. Desta forma, o planejamento de mercado foi sendo inserido nos novos planos diretores e moldando-os, a fim de competir em um mundo globalizado de fluxos financeiros intensos, voláteis e de intensas e rápidas transformações. 


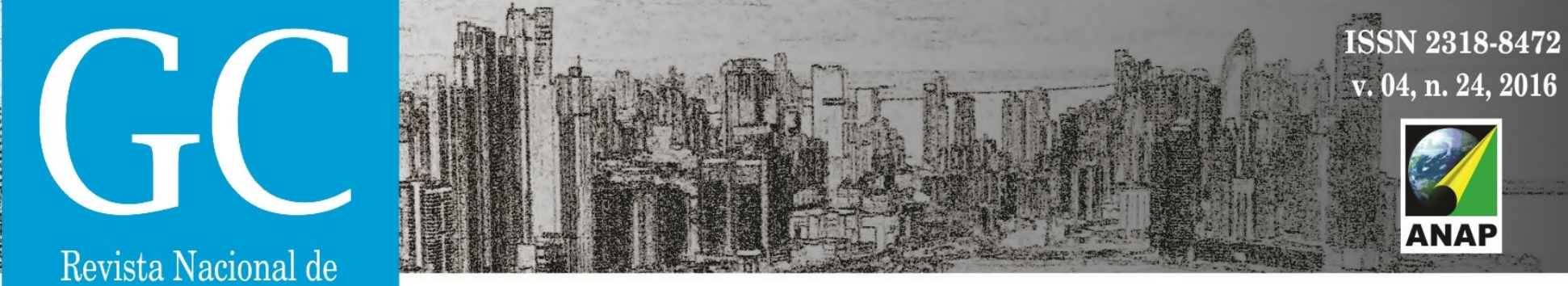

Gerenciamento de Cidades

O presente artigo busca analisar como o marketing urbano está inserido nos planejamentos estratégicos do Rio de Janeiro. Para tanto, a metodologia utilizada procurou analisar nos textos dos planos a existência dessa política e/ou a presença das ferramentas do marketing urbano citadas em PASQUOTTO (2011) que são: a arquitetura icônica, os eventos emblemáticos, as "marcas", o discurso/slogan/logotipo e a parceria público privada. Outra premissa é a verificação de como a política de promoção urbana foi utilizada em gestões diferentes ao longo dos anos.

\section{OS PLANEJAMENTOS ESTRATÉGICOS DO RIO DE JANEIRO}

O Rio de Janeiro, em sua história, desenvolveu diversas etapas no planejamento urbano, levando sempre em consideração, em maior ou menor grau, políticas de promoção urbana, como a criação de ícones e visibilidade internacional, com a contratação de consultores estrangeiros, principalmente europeus. Em 1930 iniciou-se o Plano Agache elaborado pelo arquiteto francês Alfred Hubert Donat Agache que tinha como meta "ordenar e melhorar a cidade segundo critérios funcionais de estratificação social do espaço [...] na tentativa das classes dominantes da República Velha de controlar o desenvolvimento da forma urbana carioca, já por demais contraditória" (ABREU, 1987, p. 86). Para tanto, foram realizadas obras de embelezamento com "profundas reformas urbanísticas que, já naquela época, previam a vocação do Rio de Janeiro para majestosa metrópole" (RIO ESTUDOS, 2005, p.01), apesar de segregarem ainda mais as classes sociais. Essa tendência foi seguida por diversos prefeitos e governadores com o intuito de deixar sua marca na malha urbana com a inserção de ícones e projetos urbanos, como foi o caso de Pereira Passos com a abertura da Avenida Central e a construção do Teatro Municipal.

No início da década de 60 foi realizado o Plano Doxiadis (executado durante o governo Lacerda ${ }^{1}$ e concebido pelo arquiteto e urbanista grego Constantino Doxiadis) e na década de 70 surgiu o Plano Urbanístico Básico da Cidade do Rio de Janeiro (PUBRIO). "A principal crítica ao Plano Doxiadis foi a de ser fruto de uma mentalidade colonialista desvinculada da realidade carioca, um plano elaborado por estrangeiros, com características nitidamente tecnicistas e racionalistas" (PIRES, 2010, online). Essa crítica ferrenha aos projetos internacionais em detrimento dos nacionais tem seu eco ao longo da história do planejamento da cidade, como ocorreu, por exemplo, ao projeto para o Guggenheim no píer Mauá2.

\footnotetext{
${ }^{1}$ Carlos Frederico Werneck de Lacerda, governador do estado da Guanabara de 1960 a 1965.

${ }^{2}$ Vale ressaltar que a forma de escolha do arquiteto, sem um concurso público e a qualidade do projeto foram as principais críticas, que culminaram com uma obstrução do poder judiciário.
} 


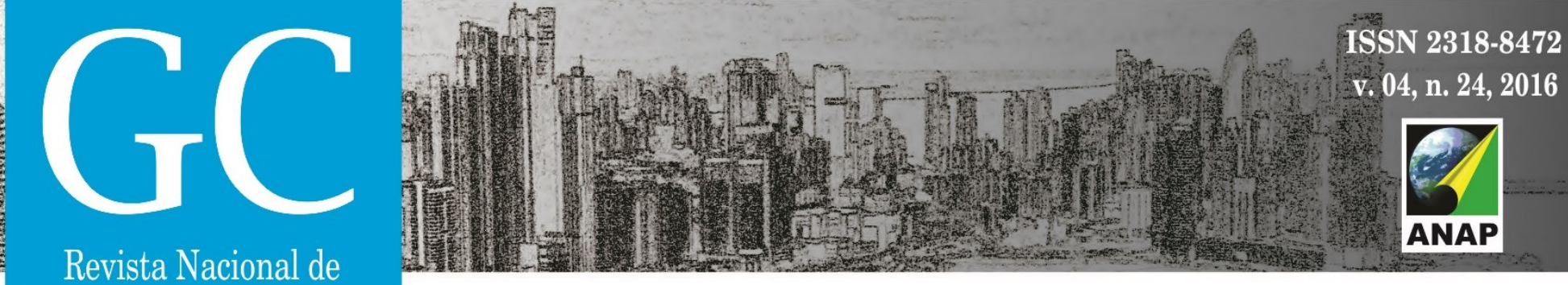

Gerenciamento de Cidades

Na década de 1990 é implantado o planejamento estratégico no Rio de Janeiro, tornando-se a primeira cidade da América Latina a organizar um plano desta ordem ${ }^{3}$. Segundo Lopes (2003, online) a decisão de mudança no enfoque de planejamento foi, principalmente, resultado da evolução mundial, exigindo uma concepção estratégica mais ampla e uma visão econômica, patrimonial e social mais completa, frente às novas realidades globais. No entanto, a decisão de mudança não recai no resultado da evolução, e sim, de novos parâmetros de competitividade e na atração de investimentos para se adequar em um mundo capitalista. Não é uma questão mais ampla, e sim, direcionada a uma estratégia empresarial, onde as ações realizadas são pensadas para "vender" o "produto cidade" utilizando das ferramentas de promoção urbana.

Segundo Magalhães (1997) essa transformação se dá, pois, "uma vez que o capitalismo contemporâneo se globaliza, globalizam-se também as estratégias para administrá-lo de maneira eficiente". Essa afirmação, embora mais próxima da realidade capitalista, é unidirecional, pois o planejamento estratégico, que possui uma metodologia empresarial, pode ser eficiente quando pensado a cidade como uma mercadoria, porém, ela é mais que isso. A cidade envolve diversos atores, que não podem ser manipulados como "joguetes" na mão de poucos para resultados benéficos a pequenos grupos que detém o poder político e/ou econômico.

O primeiro plano estratégico foi entregue em 1995 e está sendo atualizado em cada gestão, sendo utilizado até os dias atuais. Na gestão do então prefeito César Maia foram elaborados dois planos: Rio Sempre Rio (1995) e As Cidades da Cidade (2004) e na gestão do prefeito Eduardo Paes, foram redigidos mais dois volumes, em 2009 e em 2013 (Figura 01).

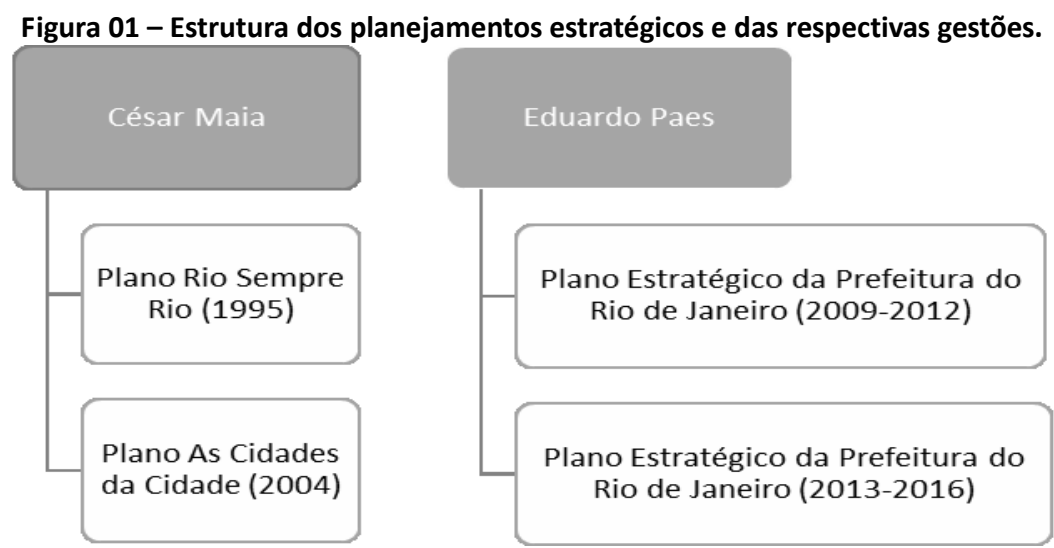

Fonte: ELABORADO PELA AUTORA, 2016.

${ }^{3}$ Outras cidades do continente americano, concomitantemente com o Rio, estavam em processo de finalização e término (Rosário) ou em providências iniciais (Montevidéo), além de outras cidades fora do Mercosul, como Bogotá, Caracas e algumas cidades da Colômbia. 


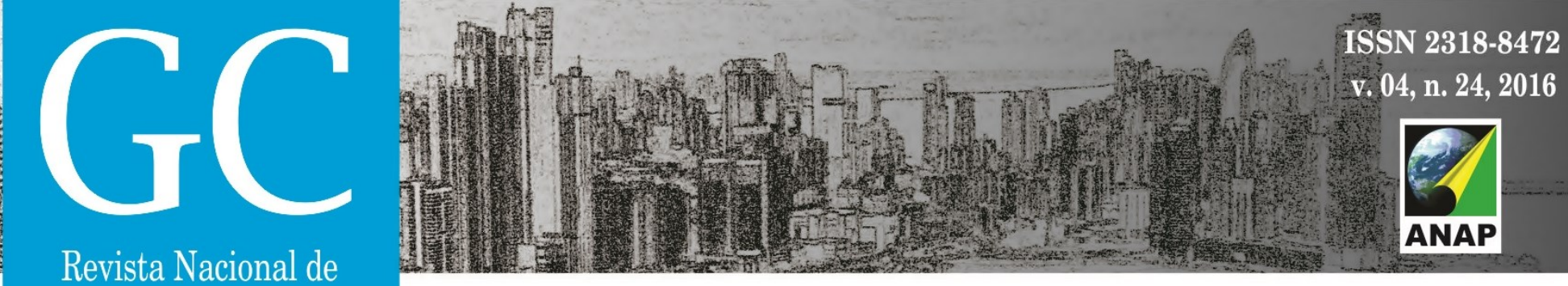

Gerenciamento de Cidades

César Maia foi prefeito da cidade do Rio de Janeiro pela primeira vez na gestão 1993-1996, possuindo uma aceitação alta da população, fato esse que é corroborado pela eleição para prefeito, na gestão seguinte (1997-2000), do ex-Secretário de Urbanismo Luiz Paulo Conde, que não possuía muita popularidade. No fim desta gestão ocorre uma ruptura política entre eles, pois Conde decidiu permanecer mais quatro anos no cargo que Maia queria novamente, o que advém em uma disputa pela autoria de projetos bem-sucedidos (GIGLIOTTI, 2010, online). César Maia volta a ser prefeito na gestão 2001-2004 e é reeleito para a gestão 2005-2008, contabilizando 16 anos de uma política pública orientada por ele.

O Rio Sempre Rio foi um consórcio caracterizado pela participação de atores sociais relevantes dos setores público e privado, numa tentativa de promoção do desenvolvimento local (GUANAIS; FISCHER, 1999, p. 39). Tinha como finalidade inicial a elaboração de um plano estratégico para a cidade, a partir do ano de 1993. A metodologia seguiu o padrão de pensamento catalão, onde foram contratados os serviços da consultoria TUBSA, cujos diretores eram Jordi Borja e Manuel de Forn.

\begin{abstract}
Luiz Paulo Conde trouxe para a gestão de César Maia, como secretário do urbanismo, a metodologia do planejamento estratégico, guiado por forte inspiração no modelo catalão aplicado na Barcelona dos Jogos Olímpicos de 1992. Sob orientação da consultoria catalã, foi elaborado o Plano Rio Sempre Rio, e com ele a concepção das cidades como lugares de troca e de colaboração participativa para a construção de um plano que atendesse às necessidades de adequação das metrópoles contemporâneas aos desafios trazidos pela globalização (CAMARGO, 2011, p.16).
\end{abstract}

Desta forma, a estrutura organizativa do Rio Sempre Rio iniciou-se em novembro de 1993 com a parceria envolvendo o Município do Rio de Janeiro (representado pelo prefeito), a FIRJAN e a ACRJ. Em 04 de Fevereiro de 1994, para dar sustentação ao processo, ajudando na elaboração do Plano Estratégico e também em termos logísticos e financeiros, foi firmada uma associação com empresas que se intitulou Consórcio Mantenedor, composto de 46 empresas de porte expressivo. Posteriormente foram criados o comitê executivo com a direção de Carlos Lessa e o Conselho Diretor (agosto de 1994) com 25 membros representativos da pluralidade econômica e social da cidade. Em outubro de 1994 foi composto o Conselho das Cidades, que englobava todos os "cidadãos representativos da sociedade carioca" (PECRJ, 1995).

Foram criados 14 grupos de trabalho com especialidades bem definidas, que objetivavam avaliar os projetos que poderiam qualificar a cidade. O Rio de Janeiro utilizou-se da criação de uma Agência de Desenvolvimento de capital público-privado", que era "capaz de financiar estudos setoriais e o desenvolvimento de projetos, a arregimentação de recursos de instituições públicas e privadas, locais e internacionais, e a negociação entre atores sociais, constituindo-se em um instrumento complementar de viabilização de ações e projetos". Outra

\footnotetext{
estratégicos.

${ }^{4}$ Cidades como Barcelona e Lisboa também utilizaram essa estrutura na implantação de seus planos
} 


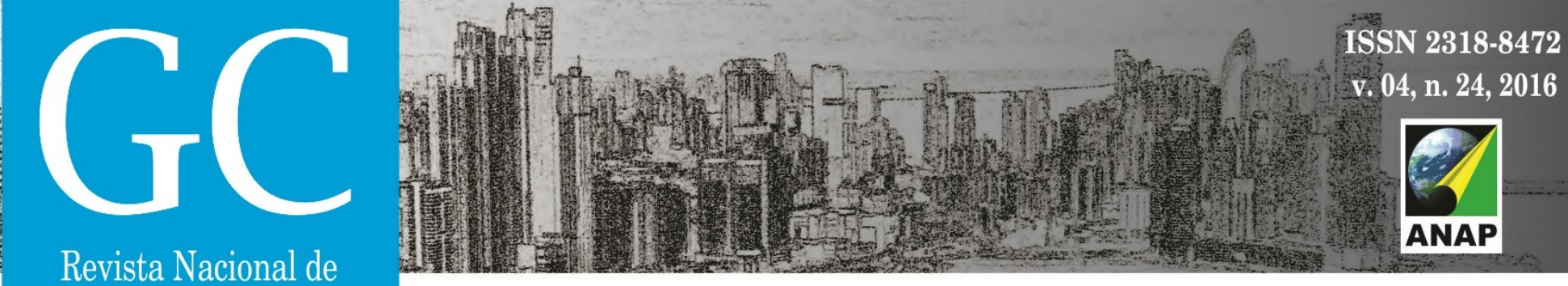

Gerenciamento de Cidades

característica dessa agência é a capacidade de intermediar os interesses públicos e privados, em negociações abertas justificadas pelos objetivos estratégicos.

O plano estratégico foi entregue em setembro de 1995 e tinha como objetivo central a integração da cidade, tornando-a atraente e competitiva, gerando uma ligação com o exterior.

\begin{abstract}
Tornar o Rio de Janeiro uma metrópole com crescente qualidade de vida, socialmente integrada, respeitosa da coisa pública e que confirme sua vocação para a cultura e a alegria de viver. Uma metrópole empreendedora e competitiva, com capacidade para ser um centro de pensamento, de geração de negócios para o país e a sua conexão privilegiada com o exterior (PECRJ, 1995, p. 22).
\end{abstract}

Foram definidas sete linhas estratégicas (Quadro 1) que levavam em consideração os serviços de saúde, educação, geração de empregos formais e de renda, incorporação de grupos fragilizados, meio ambiente, qualidade de vida nos bairros e fortalecimento de novas centralidades, melhoria dos espaços públicos, revitalização do centro da cidade, regularização fundiária, política de habitação popular, sistema viário, sistema de transporte de cargas e de passageiros, telecomunicações, canais de diálogo sociedade-governo, formação para a cidadania, sistema de justiça e segurança pública, infraestrutura e serviços de apoio a atividade produtiva, atratividade empresarial e sistemas de desenvolvimento tecnológico de empresas.

Quadro 1 - As setes linhas estratégicas desenvolvidas e seus respectivos objetivos básicos.

\begin{tabular}{|l|l|}
\hline \multicolumn{1}{|c|}{ Linhas Estratégicas } & \multicolumn{1}{c|}{ Objetivos } \\
\hline 1. O Carioca do Século XXI & - Serviços básicos e de desenvolvimento para a população. \\
\hline 2. Rio Acolhedor & $\begin{array}{l}\text { - Preservação do meio ambiente; } \\
\text { - Integração da cidade. }\end{array}$ \\
\hline 3. Rio Participativo & $\begin{array}{l}\text { - Diversificar a estrutura da administração municipal; } \\
\text { - Formação da cidadania; } \\
\text { - Segurança da cidade. }\end{array}$ \\
\hline 4. Rio Integrado & $\begin{array}{l}\text { - Comunicação rápida entre si; } \\
\text { - Tecido urbano homogêneo. }\end{array}$ \\
\hline 5. Portas do Rio & - Interligação com o entorno (sistema viário, de comunicações, etc.) \\
\hline 6. Rio Competitivo & - Atrair investimentos (melhorar a infraestrutura) \\
\hline 7. Rio 2004 & $\begin{array}{l}\text { - Tornar a cidade um polo regional, nacional e internacional; } \\
\text { - Desenvolvimento da cultura. }\end{array}$ \\
\hline
\end{tabular}

Fonte: MAIA, César. Encontro Internacional para a Integração das Mercocidades no Âmbito da Ciência e da Tecnologia, realizado no Teleporto do Rio de Janeiro nos dias 6 e 7 de maio de 1996.

Diferentemente de outras cidades, o planejamento do Rio de Janeiro neste primeiro plano não buscou a elaboração de novas vocações, e sim sua requalificação, ressaltando as vocações atuais. Essa estratégia ficou evidenciada no lema do plano que foi "Rio sempre Rio", verificando que a lógica da desarticulação das relações urbanas tende a reforçar a deterioração dos espaços, que acelera a degradação econômica e social, aumentando a decadência urbana (ZEIN, 1996).

Entretanto, na linha estratégica Rio 2004 o marketing urbano já aparece como ferramenta para o posicionamento internacional da cidade, antecipando as estratégias de inserções de ícones 
